\title{
Comunicação
}

[Communication]

\section{Leiomioma ovariano, tumor de células da granulosa e ovário policístico em cadela: uma rara associação}

[Ovarian leiomyoma, granulosa cell tumor and polycystic ovary in a bitch: a rare association]

\author{
J.N. Boeloni, J.F. Silva, E.F. Nascimento, R. Serakides, N.M. Ocarino*
}

Escola de Veterinária - Universidade Federal de Minas Gerais (UFMG) - Belo Horizonte, MG

O leiomioma é uma neoplasia mesenquimal benigna de músculo liso, frequentemente diagnosticada no trato genital, sobretudo no útero e na vagina (McLachlan e Kennedy, 2002). Sua ocorrência no ovário é rara em humanos (Khaffaf et al., 1996; Kurai et al., 2005; Tomas et al., 2009; Murakami et al., 2010; Koo et al., 2011) e em animais (Baumwart et al., 2010). Na medicina veterinária, há poucos relatos de leiomioma ovariano, sendo estes descritos em furão, na égua e na porca (Cotchin, 1980; Carstanjen et al., 2009; Baumwart et al., 2010). $\mathrm{Na}$ literatura consultada, este parece ser o primeiro relato de leiomioma ovariano em cadela. Apesar de o tumor de células da granulosa e de o ovário policístico serem patologias frequentes, a coexistência dessas alterações com o leiomioma ovariano ainda não foi descrita. Assim, o objetivo do presente relato é descrever os achados macroscópicos e microscópicos de um leiomioma ovariano associado a tumor de células da granulosa e a ovário policístico em uma cadela.

Uma cadela sem raça definida, de quinze anos de idade, não castrada, foi encaminhada ao Hospital Veterinário da Escola de Veterinária da Universidade Federal de Minas Gerais (UFMG) com suspeita de neoplasia mamária. Ao exame clínico, seis nódulos mamários, que variavam de 1 a $10 \mathrm{~cm}$ de diâmetro ao longo de toda a cadeia mamária, foram observados e, diante da suspeita de neoplasia mamária, foram solicitados exames complementares, como hemograma, perfil bioquímico (alanina aminotrasferase, aspartato aminotrasferase, fosfatase alcalina, gama

Recebido em 10 de abril de 2012

Aceito em 8 de maio de 2013

*Autor para correspondência (corresponding author)

E-mail: nataliaocarino@gmail.com glutamiltransferase, bilirrubinas totais, creatinina, ureia e glicose), raio-X torácico e ultrasonografia abdominal. $\mathrm{O}$ hemograma revelou anemia $\left(4.5 \times 10^{6}\right.$ cél. $/ \mu \mathrm{L}$ Ref: 5,5$8,55 \times 10^{6}$ cél. $\left./ \mu \mathrm{L}\right)$, o perfil bioquímico estava dentro da normalidade, o raio-X torácico não revelou a presença de metástase e a ultrassonografia abdominal revelou imagem sugestiva de ovários policísticos. Diante dos achados ultrassonográficos, o animal foi submetido à cirurgia de ovariossalpingohisterectomia, e os ovários, o útero e as tubas uterinas foram encaminhados para análise histopatológica.

Ao exame macroscópico, o ovário direito estava aumentado de volume, com aproximadamente $5 \mathrm{~cm}$ de diâmetro. Ao corte, foi evidenciada perda da arquitetura do órgão devido à presença de várias cavidades císticas preenchidas por líquido translúcido e a uma área circular brancacenta, sólida e firme, de aproximadamente $2 \mathrm{~cm}$ de diâmetro (Fig. 1A). O ovário esquerdo também se apresentava aumentado de volume, com aproximadamente $5 \mathrm{~cm}$ de diâmetro. Ao corte, foi evidenciada perda da arquitetura do órgão devido às várias cavidades císticas preenchidas por líquido translúcido (Fig. 1B). O útero e as tubas uterinas apresentavam-se macroscopicamente normais. Fragmentos dos ovários e do útero foram fixados em formalina $10 \%$ neutra e tamponada, processados pela técnica rotineira de inclusão em parafina e corados pela hematoxilina e eosina e tricrômico de Masson.

Microscopicamente, no ovário direito, observouse coexistência de três lesões. A primeira era 
caracterizada por proliferação neoplásica mesenquimal bem delimitada e expansiva, constituída por células organizadas em feixes sem estriações (Fig. 2A). As células neoplásicas apresentavam-se bem diferenciadas, com núcleo alongado, cromatina frouxa e nucléolo evidente. O citoplasma era eosinofílico, de limites imprecisos (Fig. 2A), e corou-se de vermelho pelo tricrômico de Masson, confirmando a origem muscular da neoplasia (Fig. 2B). A segunda lesão era formada por proliferação neoplásica bem delimitada de células semelhantes às células da granulosa (Fig. 2C). As células se distribuíam em padrão folicular e se organizavam de forma radial, apresentando entre elas corpúsculos de Call-Exner (Fig. 2D). O núcleo era arredondado, cromatina densa com raras figuras de mitoses. O citoplasma era escasso e de limites imprecisos (Fig. 2D). No restante do parênquima ovariano, observaram-se formações císticas multifocais delineadas por epitélio cilíndrico cúbico característico de ovário policístico (Fig. 2C). Formações císticas com a mesma característica histológica foram observadas no ovário esquerdo. O útero apresentou-se histologicamente normal.

As características histológicas observadas no presente caso demonstraram a coexistência de três lesões ovarianas, sendo elas leiomioma, tumor de células da granulosa e cistos foliculares. Importante ressaltar que os leiomiomas, por serem neoplasias benignas, não são invasivos e não causam metástases (McLachlan e Kennedy, 2002). O tumor de células da granulosa, por sua vez, normalmente é benigno, com exceção da ocorrência em gatas, e raramente ocorrem metástases para o ligamento largo, útero, peritônio e vísceras abdominais (Nascimento e Santos, 2003). O tumor de células da granulosa e os cistos foliculares são alterações frequentemente diagnosticadas nos ovários de cadela (McLachlan e Kennedy, 2002; Nascimento e Santos, 2003) e podem ser hormonalmente ativos, com produção de esteroides (estrógeno e/ou testosterona), no caso de tumor de células da granulosa, ou com produção de estrógenos, progesterona ou andrógenos, no caso dos cistos foliculares. Em cadelas com tumor de células da granulosa, é comum ocorrer hiperplasia cística endometrial e piometrite (Nascimento e Santos, 2003), enquanto cadelas com cisto folicular podem apresentar ninfomania ou irregularidade do ciclo estral, além de tumefação de vulva, hipertrofia de clitóris, ginecomastia, alopecia ventral, hiperplasia cística de endométrio e hiperplasia ou neoplasia mamária. Muitas vezes, tanto o tumor de células da granulosa quanto os cistos foliculares, por serem hormonalmente ativos, induzem a formação de leiomiomas uterinos e vaginais (Nascimento e Santos, 2003). É sabido que, em humanos, lesões ovarianas contralaterais ou episilaterais podem estar associadas com leiomiomas ovarianos (Hameed et al., 1997). Já nos animais domésticos, pelo conhecimento dos autores e na ampla literatura consultada, não há descrição de leiomioma de origem ovariana em cadela associado ou não a outras lesões ovarianas.

Em humanos, geralmente, os leiomiomas ovarianos são assintomáticos e encontrados somente durante o exame físico ou incidentamente durante cirurgias (Doss et al., 1999; Kim et al., 2000; Lim e Jeon, 2004). No presente relato, o leiomioma ovariano foi um achado incidental, durante a realização de uma ovariossalpingo-histerectomia para remoção de ovários policísticos.

Palavras-chave: neoplasia, ovário, músculo liso, cadela 

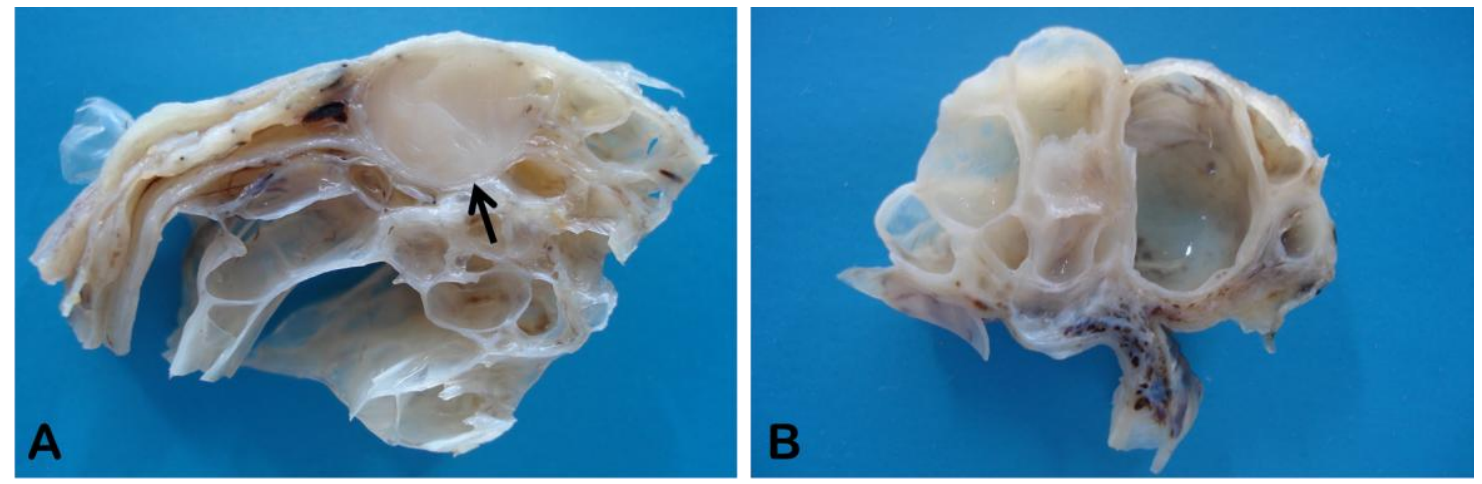

Figura 1. Leiomioma ovariano associado a tumor de células da granulosa e ovário policístico em cadela. A) Fragmento de ovário direito com nódulo brancacento (seta) correspondente ao leiomioma e com áreas císticas. B) Fragmento de ovário esquerdo cístico.
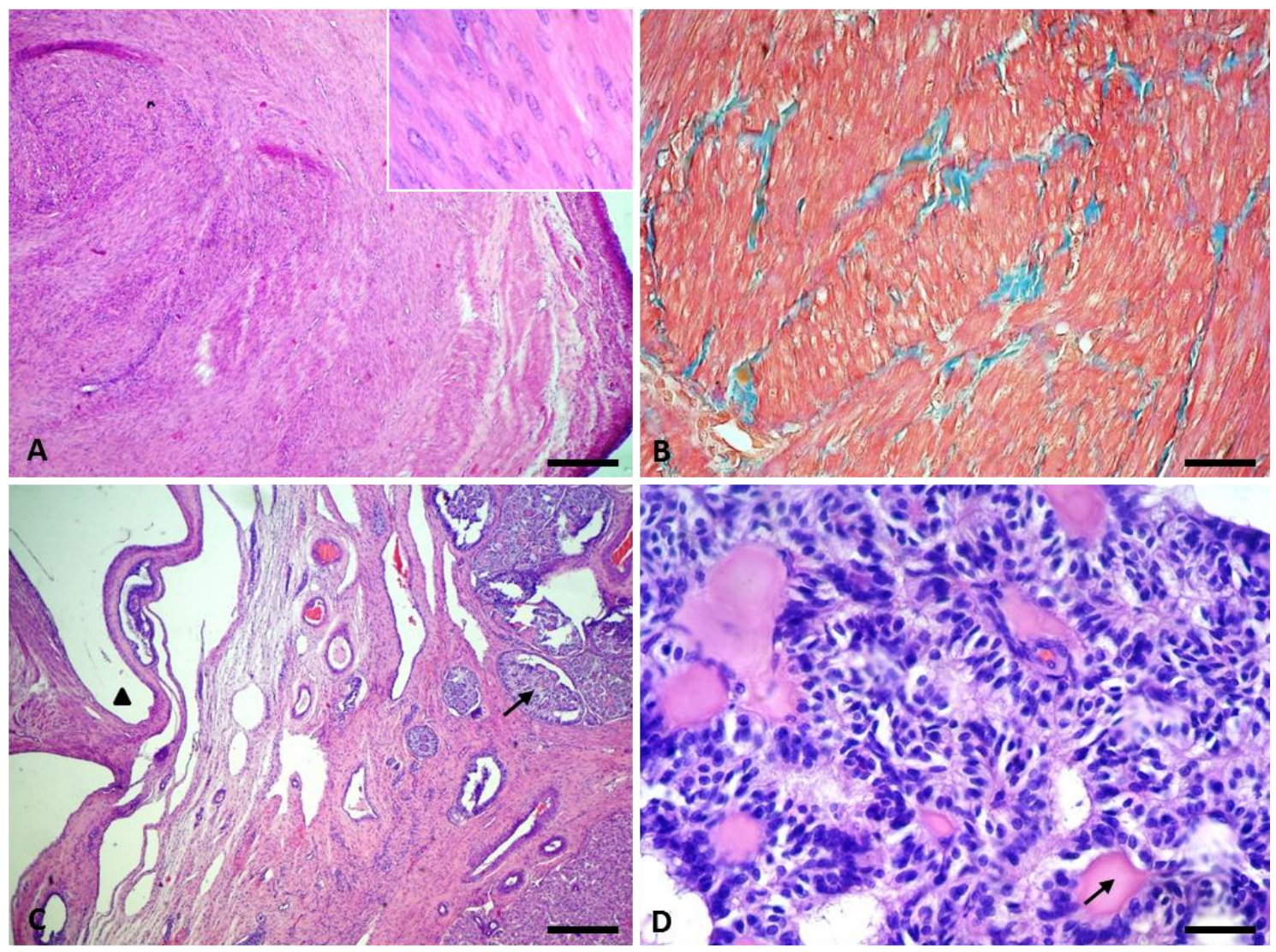

Figura 2. Leiomioma ovariano associado a tumor de células da granulosa e ovário policístico em cadela. A) Ovário direito com proliferação neoplásica mesenquimal bem delimitada, expansiva, constituída por células alongadas, citoplasma eosinofílico pouco delimitado, núcleos ovais a alongados, cromatina frouxa e nucléolo evidente (detalhe). Hematoxilina e eosina, barra $=98 \mu \mathrm{m}$. B) Células neoplásicas coradas em vermelho. Tricrômico de Masson, barra= 39,4 $\mu \mathrm{m}$. C) Ovário direito com cistos foliculares (ponta da seta) e tumor de células da granulosa com distribuição folicular (seta). Hematoxilina e eosina, barra= $112 \mu \mathrm{m}$. D) Tumor de células da granulosa apresentando núcleo arredondado, cromatina densa, citoplasma escasso e corpúsculos de Call-Exner (seta). Hematoxilina e eosina, barra=33,7 $\mu \mathrm{m}$. 


\begin{abstract}
This case describes a rare case of ovarian leiomyoma associated with granulosa cell tumor and polycystic ovary and in a fifteen-year-old mongrel female dog.
\end{abstract}

Keywords: neoplasia, ovary, smooth muscle, bitch

\section{REFERÊNCIAS}

BAUMWART, C.A.; PRADO, T.M.; ANDERSON, M.P. et al. Successful treatment of a Vietnamese potbellied pig with an ovarian leiomyoma. J. Am. Vet. Med. Assoc., v.236, p.558-561, 2010.

CARSTANJEN, B.; SCHÖNERT, S.; HEBLINSKI, N. et al. Primary unilateral fibroleiomyoma of the ovary in a pregnant mare: a case report. Reprod. Domest. Anim., v.44, p.952-957, 2009.

COTCHIN, E. Smooth-muscle hyperplasia and neoplasia in the ovaries of domestic ferrets (Mustela putorius furo). J. Pathol., v.130, p.169$171,1980$.

DOSS, B.J.; WANEK, S.M.; JACQUES, S.M. et al. Ovarian smooth muscle metaplasia: an uncommon and possibly underrecognized entity. Int. J. Gynecol. Pathol., v.18, p.58-62, 1999.

HAMEED, A.; YING, A.J.; KEYHANI-ROFAGHA, $\mathrm{S}$. et al. Ovarian mucinous cystadenoma associated with mural leiomyoma-tous nodule and massive ovarian edema. Gynecol. Oncol., v.67, p.226-229, 1997.

KHAFFAF, N.; KHAFFAF, H.; WUKETICH, S. Giant ovarian leiomyoma as a rare cause of acute abdomen and hydronephrosis. Obstet. Gynecol., v.87, p.872-873, 1996.
KIM, J.C.; NAM, S.L.; SUH, K.S. Leiomyoma of the ovary mimicking mucinous cystadenoma. Clin. Imaging, v.24, p.34-37, 2000.

KOO, Y.J.; CHO, Y.J.; KIM, J.Y. et al. Ovarian leiomyoma as a potential cause of compromised fertility. Fertil. Steril., v.95, p.e11-e14, 2011.

KURAI, M.; SHIOZAWA, T.; NOGUCHI, H. et al. Leiomyoma of the ovary presenting with Meigs' syndrome. J. Obstet. Gynaecol. Res., v.31, p.257-262, 2005.

LIM, S.C.; JEON, H.J. Bilateral primary ovarian leiomyoma in a young woman: case report and literature review. Gynecol. Oncol., v.95, p.733$735,2004$.

McLACHLAN, N.J.; KENNEDY, P.C. Tumors of the genital systems. In: MEULTEN, D.J. (Ed.). Tumors in Domestic Animals. Iowa: Iowa State Press, 2002. p.547-574.

MURAKAMI, M.; UEHARA, H.; NISHIMURA, M. et al. A huge ovarian smooth muscle tumor: a case report. J. Med. Invest., v.57, p.158-162, 2010.

NASCIMENTO, E.F.; SANTOS, R.L. Patologia da Reprodução dos Animais Domésticos. 2.ed. Rio de Janeiro: Guanabara Koogan, 2003. 137p.

TOMAS, D.; LENICEK, T.; TUCKAR, N. et al. Primary ovarian leiomyoma associated with endometriotic cyst presenting with symptoms of acute appendicitis: a case report. Diagn. Pathol., v.4, p.1746-1596, 2009. 